\title{
Dynamic Stability of Arches Impacted by Rigid Body
}

\author{
Kai QIN*, Jingyuan LI**, Mengsha LIU***, Jinsan JU**** \\ *College of Civil Engineering and Architecture, Zhejiang University, Yuhangtanglu No. 866, Xihu District, Hangzhou, \\ Zhejiang 310058, China \& BIAD Co., Ltd, No 62. Nan Li Shi Lu Xicheng District, Beijing 100045, China, \\ E-mail:1454421@qq.com \\ **China Institute of Building Standard Design \& Research, Shouti South Road No.9, Haidian District, Beijing 100048, \\ China, E-mail: lijingyuan0909@163.com \\ ***College of Water Resources and Civil Engineering, China Agricultural University, Qinghuadonglu No.17, Haidian \\ District, Beijing 100083, China, E-mail: liumengsha@cau.edu.cn \\ ****College of Water Resources and Civil Engineering, China Agricultural University, Qinghuadonglu No.17, Haidian \\ District, Beijing 100083, China, E-mail: jujinsan@cau.edu.cn (Corresponding author) \\ crossref http://dx.doi.org/10.5755/j02.mech.28300
}

\section{Introduction}

Arch, as a basic structural component like column and beam, is widely used in long span structure because of good mechanical performance. Sufficient researches have been carried out to investigate the static mechanical properties of arch structure [1-3]. But the response of arch structures under dynamic load is very limited, because its deformation, stress and vibration of three dimensions are bending-torsional-coupled, the mechanics analysis of arch structure is comprehensive [4].

Three main methods are adopted in studying the dynamic response of arch which are theoretical method, numerical method [5-6] and test method [7-8]. There are many problems to be overcome in theoretical calculation of dynamic response of arch. Firstly, the internal force, deformation and movement law of the arch under impact need to be clarified, especially the calculation method when the structure is considered as a continuum. Secondly, it is necessary to reveal the interaction between the impactor and the structure, which involves the contact dynamics [9-11].

In addition to the dynamic response of arch under impact, the dynamic stability of arch is widely concerned. Many researches are devoted to finding the critical dynamic stability state of arch under impact. The stability of the arch under impact is a dynamic problem, and it is difficult to trace the state of the arch during the whole dynamic buckling process. Therefore, scholars put forward the definition and criteria of critical dynamic stability state respectively, trying to solve the problem of when the structure becomes unstable, and on this basis, put forward their own research approaches and methods. Since it is difficult to judge the dynamic buckling of structures, studies often start from simple components such as bars to try to solve the problems of buckling mode and critical load of components [12-13].

The analytic solutions of the arches' dynamic response considering the initial condition and boundary conditions are gotten based on series simplified dynamic differential equations with different hypotheses. Previous investigations on the dynamic buckling of arches are carried out with a rigid-plastic material model assumption and the structural deformation become relatively simple for analysis [14-15]. However, this method is applicable for the dynamic mechanical calculation when the structure undergoes small deformation. Further study [16-17] has been carried out which is suitable for structures with maximum deformation.
In order to simplify calculating, the calculation model of arches with 5 hinge joints is set up to analyze the dynamic response of arch under impact load on the vault [18]. With energy methods, Y. L. Pi [19-20] brought series studies about nonlinear dynamic buckling of arch under different boundary conditions. It is considered that the kinetic energy of arch is zero at the critical dynamic state and the dynamic problem is transformed into a static one and dynamic buckling load is obtained in these studies.

Because of the application of energy method in judging the dynamic stability of structure, it can be known that the energy of structure has certain characteristics when dynamic instability occurs. It is very convenient to derive the variation of energy of structures based on numerical method. Therefore, finite element analysis method is used in this article to investigate the energy characteristics of arch under impact by rigid body considering the effect of material non-linear, geometric non-linear and contact non-linear. Based on the energy characteristics, a method for determining the critical dynamic instability of arch is presented.

\section{Numerical analysis of elastic arch under impact}

Under the vertical impacted by rigid body, the motion status of arches and the impact loads varying with time are studied. The numerical analyses of elastic arches when impact hammer act vertically on are carried out in Abaqus/Explicit in this study. The arch modeled is in $30 \mathrm{~m}$ span and in 0.15 rise to span ratio, and the cross section of the arch is rectangular which is $0.8 \mathrm{~m}$ and $1 \mathrm{~m}$ in width and length. The arch is established by using two nodes elastic beam element BEAM31 and the arch is divided into 300 elements. The impact hammer is simulated with a rigid body which is a circular plate with diameter in $0.8 \mathrm{~m}$. Contact force between rigid body and arch is extracted in numerical simulation as the impact load. The position relation of the arch and the impact hammer is shown in Fig. 1. The arch is hinged at both ends and the displacements in $\mathrm{X}, \mathrm{Y}$ and $\mathrm{Z}$ directions at the supports are constrained in the calculation. In addition, the out-of-plane displacement of the arch is constrained (The z-direction displacement is constrained).

The material property of steel arch is elastic whose density is $7800 \mathrm{~kg} / \mathrm{m}^{3}$, Young's modulus is $210 \mathrm{GPa}$ and Poisson ratio is 0.3 .

When the rigid body is in relatively smaller mass, $2 \mathrm{e}^{5} \mathrm{~kg}$, for example, the mass ratio of impactor to arch is 


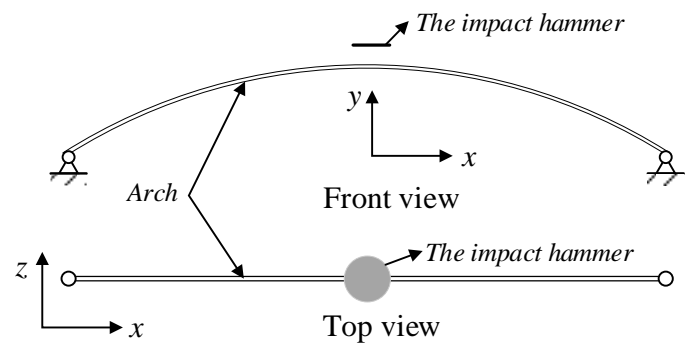

Fig. 1 The arch and the impact hammer

\subsection{The impact load varying with time}

approximately $1: 1$, and the impact velocity is also relatively small which is in $20 \mathrm{~m} / \mathrm{s}$, the time history curve of impact load acting on the arch is shown in Fig. 2, a. The impact loads the arch bearing shown in Fig. 2, a has experienced three pulses, in which the first amplitude is large, the latter two amplitudes are small. The impact load returns to zero value after the first pulse, which means that the impactor briefly separates from the arch after the first contact, and then the second contact followed happened. The impactor is completely separated from the arch after the second contact and the impact load returns to zero. Thus, in the whole process of rigid body vertical impact, many times of contact and separation between the impactor and arch happened. Impact acting on arch from rigid body with a relatively small velocity and mass won't led to the dynamic instability of the arch which can be observed from the vertical motion status of the arch crown shown as Fig. 2, b. The time-history curve of vault displacement for the analysis model above is shown in Fig. 2, b and the arch is vibrating with a small amplitude about its initial position without instability shown as Fig. 2, b.

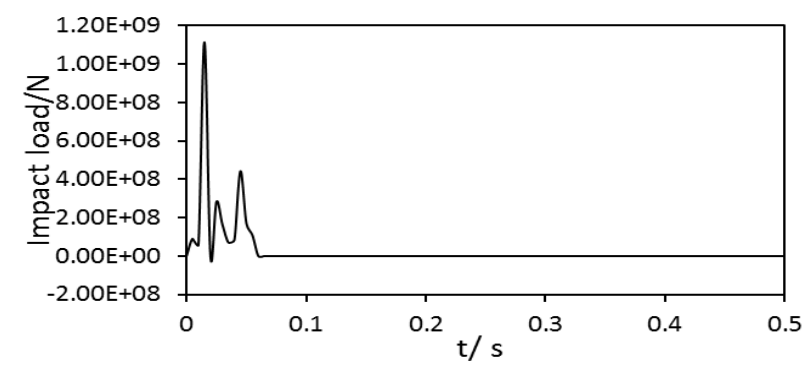

a

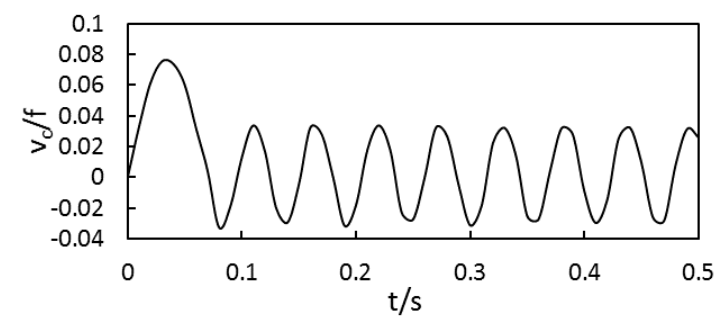

b

Fig. 2 The curves of impact load and crown displacement varying with time under impact when impact mass is $2 \mathrm{e}^{5} \mathrm{~kg}$ and impact velocity is $20 \mathrm{~m} / \mathrm{s}$ : a) Impact load time history curve; b) Crown displacement time history curve

The mass of the impactor is adjusted to $6 \mathrm{e}^{6} \mathrm{~kg}$, and the mass ratio of the impactor to the arch is about 30:1. When the rigid body act on the arch with a relatively small velocity of $15 \mathrm{~m} / \mathrm{s}$, the time history curve of the impact load is shown in Fig. 3, a. It could be observed from Fig. 3, a that the impact load won't return to zero value during the contact process and the rigid body won't separate away from the arch until the impact process finishes. The time-history curve of vault displacement in Fig. 3, b shows that the arch also vibrates with a small amplitude about its initial position after impact without instability.

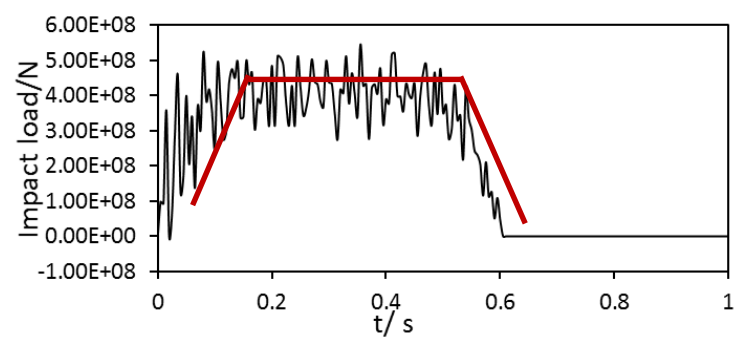

a

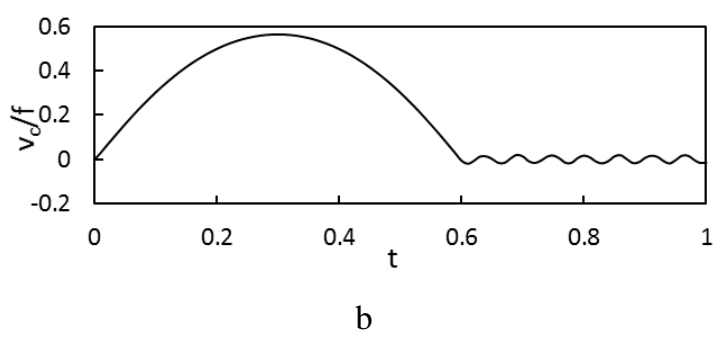

Fig. 3 The curves of impact load and crown displacement varying with time under impact when impact mass is $6 \mathrm{e}^{6} \mathrm{~kg}$ and impact velocity is $15 \mathrm{~m} / \mathrm{s}$ : a) Impact load time history curve; b) Crown displacement time history curve

When the impact velocity of the rigid body increases to $20 \mathrm{~m} / \mathrm{s}$, the time history curve of impact load is shown as Fig. 4, a and the time-history curve of the vault displacement is shown in Fig. 4, b.

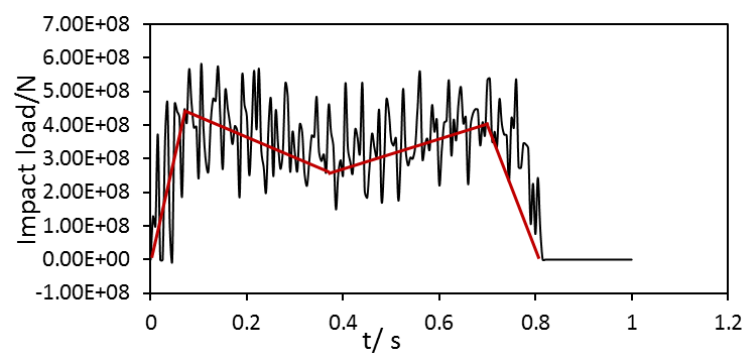

a

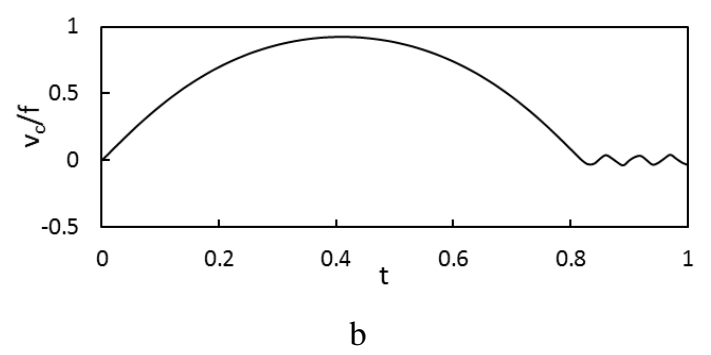

Fig. 4 The curves of impact load and crown displacement varying with time under impact when impact mass is $6 \mathrm{e}^{6} \mathrm{~kg}$ and impact velocity is $20 \mathrm{~m} / \mathrm{s}$ : a) Impact load time history curve; b) Crown displacement time history curve 
The arch still doesn't buckle which can be observed from Fig. 4, b. Similarly, the whole impact process is only one collision, during which the impact hammer and the arch are not separated. The arch moves to its extreme position at the time of $0.41 \mathrm{~s}$ shown as Fig. 4 , b and at that time, the trend of the impact load changed shown as Fig. 4, a. The contact force decreases with the vault moving downwards and the contact force reaches the minimum when the vault reaches its extreme position at the time of $0.41 \mathrm{~s}$. Then the vault begins to move upward, and the contact force increases in the following process. The increment of the contact force between the impactor and the arch is due to the velocity moving upward of the vault is larger than that of the impactor until the difference of the velocity between them decreasing to zero. And then, the impactor is gradually separated from the arch which can observed from Fig. 4, a that the impact load is reduced to zero. After the impact process, the arch returns to its initial position and vibrates with a small amplitude about this position. The time-history curve of the impact load is a form which looks like the letters "M" shown as Fig. 4, a.

With the increasing of the impact velocity of the rigid body, the impact load corresponding to the state when the vault reaches its extreme position decreases with values that die out to zero. Ideally, when the arch is impacted by the impactor with the critical velocity of dynamic instability, the motion of the arch almost stopped at its critical stable state and the impactor separated from the arch simultaneously. Thus, the contact force drops to zero and the time history curve of the impact load just completes half of the "M" shape, which is shown as a triangle. And at that state, the kinetic energy of the system is minimized and the kinetic energy and potential energy of the impactor are almost transformed into the strain energy of the arch. When the arch reaches the stable critical state under impact, a small upward excitation can make it move to the initial position without instability and a small downward excitation can make it move away from the initial position and cause dynamic instability.

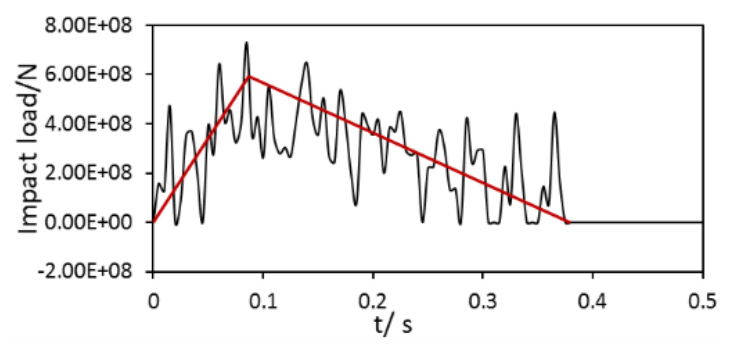

a

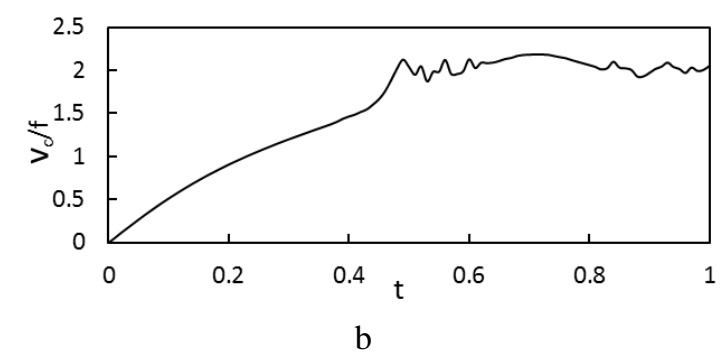

Fig. 5 The curves of impact load and crown displacement varying with time under impact when impact mass is $6 \mathrm{e}^{6} \mathrm{~kg}$ and impact velocity is $25 \mathrm{~m} / \mathrm{s}$ : a) Impact load time history curve; b) Crown displacement time history curve
When the impact velocity of the rigid body increases to $25 \mathrm{~m} / \mathrm{s}$, instability of extreme point type for the arch will occur under impact which can be observed from the motion state of the vault which will keep moving until losing stability other than return to its initial position shown as Fig. 5, b. Shown as Fig. 5, a, the whole impact process is completed in one impact contact. The form of the time-history curve of the impact load changed to triangle shown as Fig. 5, a and the arch will continue moving after the impactor is separated from the arch until reaching the extreme position.

Thus, the forms of impact load can be roughly divided into the following three categories. First, multiple pulses with amplitude variation form under a little mass impact shown as Fig. 2, a. Second, the "M" form shown as Fig. 4, a when the impact mass is larger, and the impact velocity is smaller than the dynamic stability critical impact velocity and the last category is the triangular impact load shown as Fig. 5, a when the impact mass is larger, and the impact velocity is great than or equal to the dynamic stability critical impact velocity.

\subsection{Dynamic stable critical state}

The dynamic stable critical state of arches can be obtained by repeating trial-calculation. The finite element model analyzed in this section is in $30 \mathrm{~m}$ span and in 0.15 rise to span ratio, and the cross section of the arch is rectangular which is $0.8 \mathrm{~m}$ and $1 \mathrm{~m}$ in width and length.

As mentioned above, there are many factors that affect the forms of impact load. When impact mass is relatively large, the time history curve of the impact load in the state of arch for dynamic instability is close to triangle in shape. At first, six groups of trial calculations were performed for the arch under the relatively great mass impact whose values range from $2 \mathrm{e}^{6} \mathrm{~kg}-1.2 \mathrm{e}^{7} \mathrm{~kg}$. Some of the numerical simulation results are shown in Fig. 6 and critical impact velocities for ranges of impact masses are listed in Table 1.

Table 1

Dynamic stability critical impact velocity

\begin{tabular}{|c|c|}
\hline Impact mass $/ \mathrm{kg}$ & critical impact velocity $/ \mathrm{m} / \mathrm{s}$ \\
\hline $2.00 \mathrm{E}+06$ & 43.3 \\
\hline $4.00 \mathrm{E}+06$ & 30.5 \\
\hline $6.00 \mathrm{E}+06$ & 25 \\
\hline $8.00 \mathrm{E}+06$ & 21.5 \\
\hline $1.00 \mathrm{E}+07$ & 19.2 \\
\hline $1.20 \mathrm{E}+07$ & 17.5 \\
\hline
\end{tabular}

The critical impact velocities shown in Table 1 are obtained by interpolation approximation as shown in Fig. 6 . The movements of the arch crown under impact applied when the dynamic stability critical state of the arch is reached are indicated by the black solid curves shown in Fig. 6. It could be observed from Table 1 that the critical impact velocity decreases with the increase of the impact mass.

The impact load produced by the impact of a rigid body with a smaller mass is different with that a rigid body with a large mass which is in the form of multiple pulses with amplitude variation shown as Fig. 2, a, but the state of the arch can also be determined by the movement of the arch crown which can be observed form the time-history curves 
of arch crown's vertical displacement. The dynamic stable critical state when impact in small mass applied is gotten by repeating trial-calculation with finite element method shown as Fig. 7 and the critical impact critical impact velocities corresponding to varies of impact mass whose values range from $2 \mathrm{e}^{5} \mathrm{~kg}-1.2 \mathrm{e}^{6} \mathrm{~kg}$ are shown in Table 2 . Similarly, with the increase of impact mass, the dynamic stability critical impact velocity decreases.

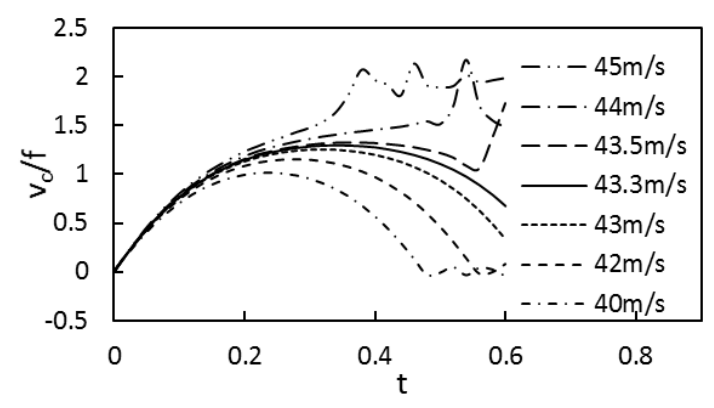

a

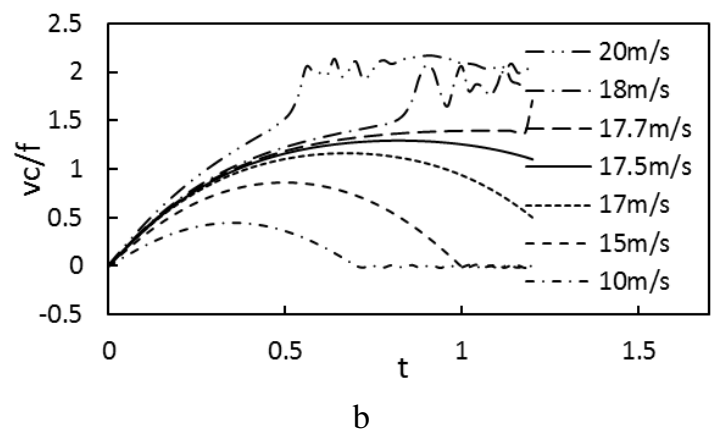

Fig. 6 The curves of crown displacement varying with time under impact when the impact mass is relatively large: a) Impact mass $=2 \mathrm{e}^{6} \mathrm{~kg}$; b) Impact mass $=$ $=1.2 \mathrm{e}^{7} \mathrm{~kg}$

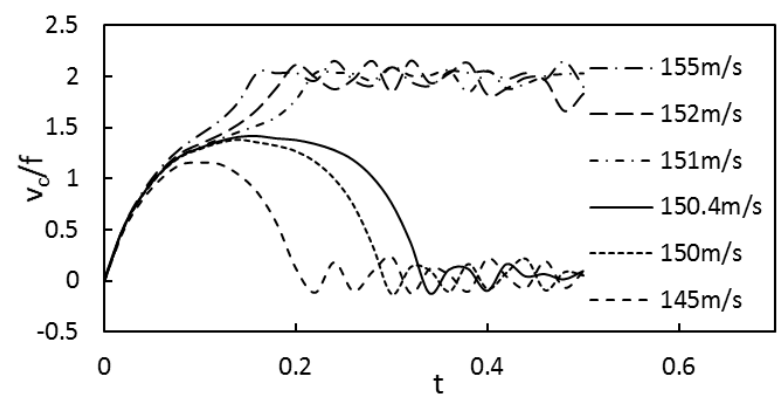

a

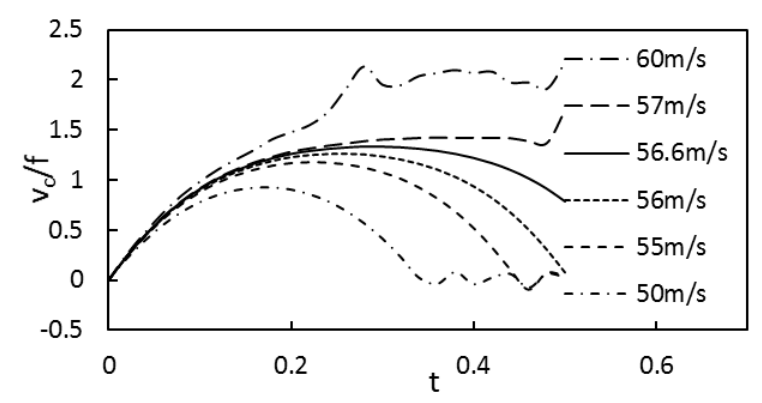

b

Fig. 7 The curves of crown displacement varying with time under impact when the impact mass is relatively small a) Impact mass $=2 \mathrm{e}^{5} \mathrm{~kg}$; b) Impact mass= $=1.2 \mathrm{e}^{6} \mathrm{~kg}$
Table 2

Dynamic stability critical impact velocity

\begin{tabular}{|c|c|}
\hline Impact mass, $\mathrm{kg}$ & Critical impact velocity, $\mathrm{m} / \mathrm{s}$ \\
\hline $2.00 \mathrm{E}+05$ & 150.4 \\
\hline $4.00 \mathrm{E}+05$ & 101.9 \\
\hline $6.00 \mathrm{E}+05$ & 81.6 \\
\hline $8.00 \mathrm{E}+05$ & 70.2 \\
\hline $1.00 \mathrm{E}+06$ & 62.2 \\
\hline $1.20 \mathrm{E}+06$ & 56.6 \\
\hline
\end{tabular}

2.3. Energy characteristics of arches at dynamic stability critical state

As discussed above, in the ideal dynamic stability critical state of arches under impact by rigid bodied, the arch will almost stop moving, and the kinetic energy of the system is minimized and the kinetic energy and potential energy of the impactor are almost transformed into the strain energy of the arch. The kinetic energy and strain energy of arches analyzed in in the above section when impact applied are listed in Table 3 . It could be observed from Table 3 that the kinetic energies of arches are so smaller than strain energies that the ratios of kinetic energies to strain energies are no more than $1.2 \%$ and besides that, the strain energies of arches under different initial impact conditions are close in value. The converter efficiencies for kinetic energy of the impactor that transformed into the strain energy of the arch in the ideal dynamic stability critical state are also listed in Table 3. The converter efficiencies for kinetic energy approaches $100 \%$. Thus, when the geometry of the arch is constant, the initial energies possessed by the impactors which will led the arches reaching the dynamic stability critical state are roughly the same according to Table 3.

As known from the above analysis, the state of arches can be determined by the strain energy of the arch after impact and the critical strain energy is fixed when the geometry of the arch is constant. The strain energies of arches at dynamic stability critical state under impact are close to that of a state for the arch when static central radial load applied on arch shown as point B in Fig. 8, in which the curve of static load-crown displacement is given. The static analysis is obtained by Abaqus/Static, RIKS. The arch moving to the state at point A shown in Fig. 8 is reaching its static stability critical state and after that state, the arch buckle accompanied by the decrease of bearing capacity. The bearing capacity of the arch is completely lost when it reached the position of point $B$ and the arch will make a sudden jump from the configuration at point $B$ to that at point C. The strain energy of arches at dynamic stable critical state are compared with that at the state of the arches in the same geometry under static load corresponding to point B shown as Table 4 . It could be observed from that table the differences between them are very small and no more than $3.6 \%$.

From the foregoing comparison, the strain energy of arches under static load at the state corresponding to point B in Fig. 8 can be accurately estimated the strain energy of the arch at dynamic stable critical state in the same geometry. When the geometric dimension is determined, the loaddeformation relationship shown as Fig. 8 of the arch is unique [17-18] and the strain energy can be obtained. Considering that the initial energy possessed by the impactor which will led the arch reaching the dynamic stability critical state is fixed and almost equal to the strain energy of 
arches at dynamic stable critical state when the geometry of the arch is constant, the initial condition of the impact the arch can bear can be determined.

Table 3

Energy characteristics of arches when impact applied

\begin{tabular}{|c|c|c|c|c|c|c|c|}
\hline $\begin{array}{c}\text { Impact } \\
\text { mass, } \mathrm{kg}\end{array}$ & $\begin{array}{c}\text { Impact } \\
\text { velocity, } \\
\mathrm{m} / \mathrm{s}\end{array}$ & $\begin{array}{c}\text { Kinetic energy } \\
\text { of arches at dy- } \\
\text { namic stable } \\
\text { critical state, J }\end{array}$ & $\begin{array}{c}\text { Strain energy of } \\
\text { arches at dynamic } \\
\text { stable critical state, J }\end{array}$ & $\begin{array}{c}\text { Kinetic energy / } \\
\text { Strain energy at } \\
\text { dynamic stable } \\
\text { critical state of } \\
\text { arches }\end{array}$ & $\begin{array}{c}\text { Artificial strain } \\
\text { energy, J }\end{array}$ & $\begin{array}{c}\text { Initial kinetic } \\
\text { energy of the } \\
\text { impactor, J }\end{array}$ & $\begin{array}{c}\text { The energy con- } \\
\text { version rate after } \\
\text { removing the ar- } \\
\text { tificial strain en- } \\
\text { ergy }\end{array}$ \\
\hline $2.00 \mathrm{E}+05$ & 150.4 & $2.1018 \mathrm{E}+07$ & $1.9006 \mathrm{E}+09$ & $1.106 \%$ & $3.3852 \mathrm{E}+08$ & $2.2620 \mathrm{E}+09$ & $98.81 \%$ \\
\hline $4.00 \mathrm{E}+05$ & 101.9 & $1.1467 \mathrm{E}+07$ & $1.8836 \mathrm{E}+09$ & $0.609 \%$ & $1.7670 \mathrm{E}+08$ & $2.0767 \mathrm{E}+09$ & $99.14 \%$ \\
\hline $6.00 \mathrm{E}+05$ & 81.6 & $1.2173 \mathrm{E}+07$ & $1.8631 \mathrm{E}+09$ & $0.653 \%$ & $1.1637 \mathrm{E}+08$ & $1.9976 \mathrm{E}+09$ & $99.04 \%$ \\
\hline $8.00 \mathrm{E}+05$ & 70.2 & $4.6105 \mathrm{E}+06$ & $1.8591 \mathrm{E}+09$ & $0.248 \%$ & $1.0124 \mathrm{E}+08$ & $1.9712 \mathrm{E}+09$ & $99.42 \%$ \\
\hline $1.00 \mathrm{E}+06$ & 62.2 & $4.6476 \mathrm{E}+06$ & $1.8487 \mathrm{E}+09$ & $0.251 \%$ & $7.4789 \mathrm{E}+07$ & $1.9344 \mathrm{E}+09$ & $99.41 \%$ \\
\hline $1.20 \mathrm{E}+06$ & 56.6 & $4.9354 \mathrm{E}+06$ & $1.8479 \mathrm{E}+09$ & $0.267 \%$ & $6.2502 \mathrm{E}+07$ & $1.9221 \mathrm{E}+09$ & $99.37 \%$ \\
\hline $2.00 \mathrm{E}+06$ & 43.3 & $3.4802 \mathrm{E}+06$ & $1.8302 \mathrm{E}+09$ & $0.190 \%$ & $3.4376 \mathrm{E}+07$ & $1.8749 \mathrm{E}+09$ & $99.44 \%$ \\
\hline $4.00 \mathrm{E}+06$ & 30.5 & $2.7921 \mathrm{E}+06$ & $1.8349 \mathrm{E}+09$ & $0.152 \%$ & $1.5917 \mathrm{E}+07$ & $1.8605 \mathrm{E}+09$ & $99.48 \%$ \\
\hline $6.00 \mathrm{E}+06$ & 25 & $4.2366 \mathrm{E}+05$ & $1.8558 \mathrm{E}+09$ & $0.023 \%$ & $1.1672 \mathrm{E}+07$ & $1.8750 \mathrm{E}+09$ & $99.60 \%$ \\
\hline $8.00 \mathrm{E}+06$ & 21.5 & $2.8183 \mathrm{E}+06$ & $1.8331 \mathrm{E}+09$ & $0.154 \%$ & $5.8519 \mathrm{E}+06$ & $1.8490 \mathrm{E}+09$ & $99.46 \%$ \\
\hline $1.00 \mathrm{E}+07$ & 19.2 & $1.1486 \mathrm{E}+06$ & $1.8296 \mathrm{E}+09$ & $0.063 \%$ & $5.2161 \mathrm{E}+06$ & $1.8432 \mathrm{E}+09$ & $99.54 \%$ \\
\hline $1.20 \mathrm{E}+07$ & 17.5 & $1.0082 \mathrm{E}+06$ & $1.8256 \mathrm{E}+09$ & $0.055 \%$ & $3.8097 \mathrm{E}+06$ & $1.8375 \mathrm{E}+09$ & $99.56 \%$ \\
\hline
\end{tabular}

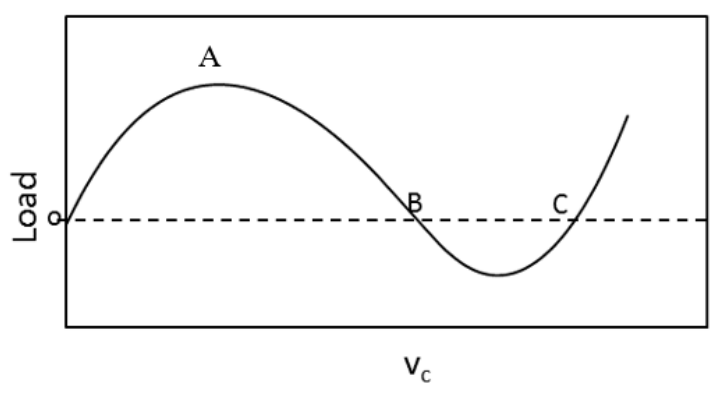

Fig. 8 Load-displacement curve of arch under static load

Table 4

The elastic strain energy of arches

\begin{tabular}{|c|c|c|c|c|}
\hline $\begin{array}{c}\text { Impact } \\
\text { mass, kg }\end{array}$ & $\begin{array}{c}\text { Critical } \\
\text { impact } \\
\text { veloc- } \\
\text { ity, m/s }\end{array}$ & $\begin{array}{c}\text { Strain energy at } \\
\text { dynamic stable } \\
\text { critical, J }\end{array}$ & $\begin{array}{c}\text { Strain energy } \\
\text { of point B on } \\
\text { static bal- } \\
\text { anced route, J }\end{array}$ & $\begin{array}{c}\text { Percent- } \\
\text { age val- } \\
\text { ues of } \\
\text { the dif- } \\
\text { ferences }\end{array}$ \\
\hline $2.00 \mathrm{E}+05$ & 150.4 & $1.9006 \mathrm{E}+09$ & $1.8923 \mathrm{E}+09$ & $0.44 \%$ \\
\hline $4.00 \mathrm{E}+05$ & 101.9 & $1.8836 \mathrm{E}+09$ & $1.8923 \mathrm{E}+09$ & $-0.46 \%$ \\
\hline $6.00 \mathrm{E}+05$ & 81.6 & $1.8631 \mathrm{E}+09$ & $1.8923 \mathrm{E}+09$ & $-1.54 \%$ \\
\hline $8.00 \mathrm{E}+05$ & 70.2 & $1.8591 \mathrm{E}+09$ & $1.8923 \mathrm{E}+09$ & $-1.75 \%$ \\
\hline $1.00 \mathrm{E}+06$ & 62.2 & $1.8487 \mathrm{E}+09$ & $1.8923 \mathrm{E}+09$ & $-2.30 \%$ \\
\hline $1.20 \mathrm{E}+06$ & 56.6 & $1.8479 \mathrm{E}+09$ & $1.8923 \mathrm{E}+09$ & $-2.35 \%$ \\
\hline $2.00 \mathrm{E}+06$ & 43.3 & $1.8302 \mathrm{E}+09$ & $1.8923 \mathrm{E}+09$ & $-3.28 \%$ \\
\hline $4.00 \mathrm{E}+06$ & 30.5 & $1.8349 \mathrm{E}+09$ & $1.8923 \mathrm{E}+09$ & $-3.03 \%$ \\
\hline $6.00 \mathrm{E}+06$ & 25 & $1.8558 \mathrm{E}+09$ & $1.8923 \mathrm{E}+09$ & $-1.93 \%$ \\
\hline $8.00 \mathrm{E}+06$ & 21.5 & $1.8331 \mathrm{E}+09$ & $1.8923 \mathrm{E}+09$ & $-3.13 \%$ \\
\hline $1.00 \mathrm{E}+07$ & 19.2 & $1.8296 \mathrm{E}+09$ & $1.8923 \mathrm{E}+09$ & $-3.32 \%$ \\
\hline $1.20 \mathrm{E}+07$ & 17.5 & $1.8256 \mathrm{E}+09$ & $1.8923 \mathrm{E}+09$ & $-3.53 \%$ \\
\hline
\end{tabular}

\section{Numerical analysis of elastic-plastic arch under im- pact}

The arch used in this section for studying the mechanical properties of elastic-plastic arch under impact is same in dimensions as section 2 and the numerical simulations are carried out with the same software as section 2 . The material property of arches in this section is perfect elasticplastic steel whose Young's modulus is $210 \mathrm{GPa}$, yield strength is $235 \mathrm{MPa}$ and Poisson ratio is 0.3 .

\subsection{The impact load varying with time}

The time history curves of impact load acting on the arch under impact with different initial conditions in impact velocity and mass are shown in Fig. 9 by finite element analyses. The number M1.2E5V11 in Fig. 9 means that the impactor is $1.2 \mathrm{e}^{5} \mathrm{~kg}$ in mass and $11 \mathrm{~m} / \mathrm{s}$ in velocity and so on.

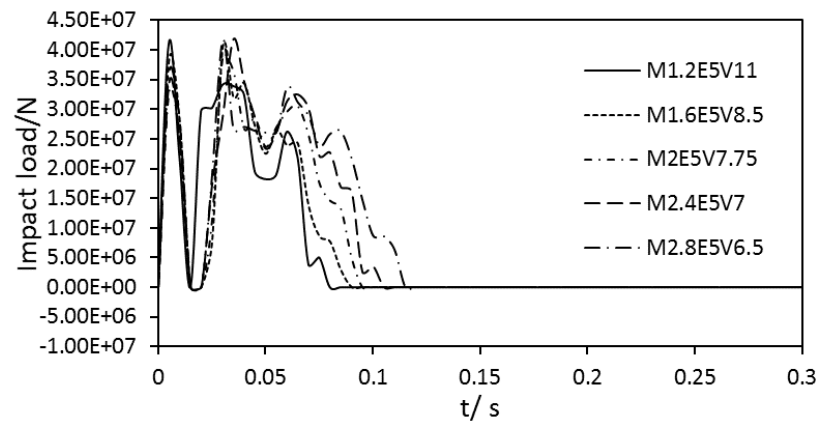

Fig. 9 The impact load of elastic-plastic arches under impact

The time history curves of impact load acting on the arch under impact with different initial conditions in impact velocity and mass are shown in Fig. 9 by finite element analyses. The number M1.2E5V11 in Fig. 9 means that the impactor is $1.2 \mathrm{e}^{5} \mathrm{~kg}$ in mass and $11 \mathrm{~m} / \mathrm{s}$ in velocity and so on.

\subsection{Dynamic stable critical state}

For elastic arches, the dynamic instability of the arch can be determined by whether the arch snaps through or not, if the elastic arch does not snap through after impact, 
it will eventually return to the initial position and vibrate with small amplitude shown as Fig. 6 without losing stability. If the plasticity of the material is taken into account, the plastic deformation will not disappear with the disappearance of the external load. The elastic-plastic instability process under static load applied is shown in Fig. 10.

Four inflection points can be observed from the load-displacement curve of elastic-plastic arch shown as Fig. 10, a and four inflection points can also be found in the elastic strain energy-displacement curve correspondingly shown as Fig. 10, b. The expanding law of plastic region of the arch under the central radial static load applied corresponding to the state of the four inflection points in Fig. 10 are shown as Fig. 10.

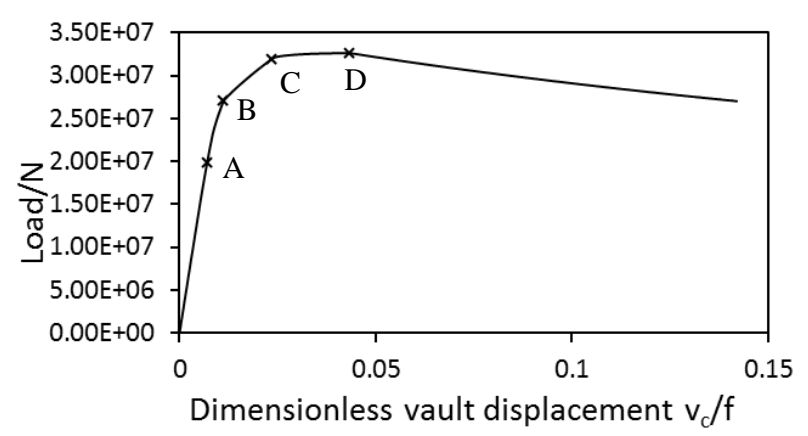

$\mathrm{a}$

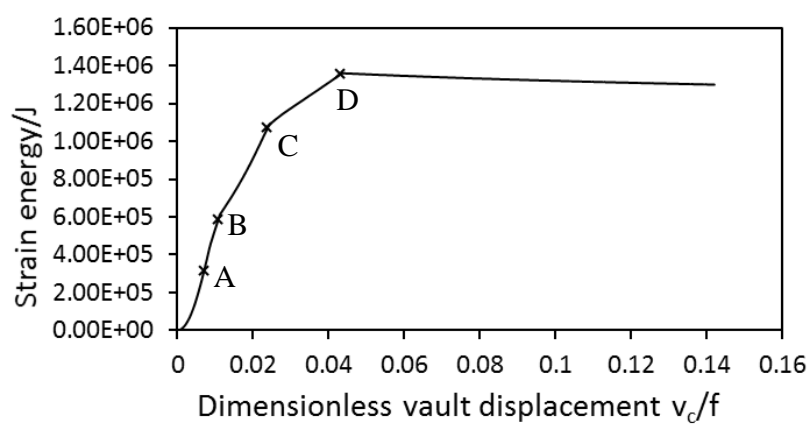

b

Fig. 10 The load and elastic strain energy-displacement curve of elastic-plastic arch when static load applied

From Fig. 11, A to Fig. 11, D, it shows that the state of arch is from the beginning of the static load applied to structural instability occurred. The arch worked in elastic behavior before the state shown as Fig. 10, A reached and the load-displacement curve is linear. The arch's crown yields firstly at the state shown as Fig. 11, A and with the structural configuration changes shown as Fig. 11, B, the force state of the arch is changing from state A to state B which cause the internal force redistribution and the plastic region changing. Thus, the slope of the load-displacement curve shown in Fig. 10, a changes significantly. When the structure moves to the state shown as Fig. 11, B, the stiffness of the structure decreased significantly and the plastic region expands rapidly to the state shown as Fig. 11, C, and then, the plastic region expansion basically stops and the bearing capacity reaches the limit value shown as Fig. 10, a. But elastic strain energy steel increase after the state shown as Fig. 10, b, that is due to the crown's vertical displacement is still increasing until the plastic hinges is formed at $1 / 4$ and 3/4 span shown as Fig. 11, D. The structure moves around the plastic hinge after the state shown as Fig. 11, D, and crown's vertical displacement increase rapidly accompanied by structural instability. After the state shown as Fig. 11, D, the work done by the external force is mainly transformed into plastic dissipation.
A

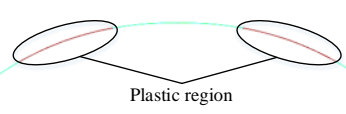

C

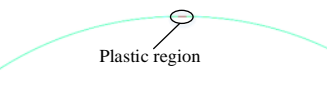

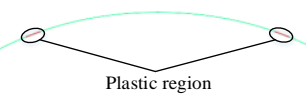

B

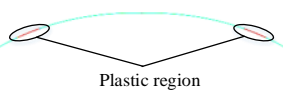

D
Fig. 11 The expanding law of plastic region and the deformation characteristics of the arches

The expanding law of plastic region and the deformation characteristics of the arches under impact are the same with that when static load applied shown as Fig. 11. At first, the arch yields at crown, and then the plastic region moves to about $1 / 4$ of both sides of the arch and with the extension of the yield region, the stiffness of the arch decreases significantly. Finally, with the rapid concentration of plastic regions on both sides of the arch, plastic hinges are formed and the arch reaches the stable critical state. The arch working in elastic behavior can return to it's initial state without affecting the bearing capacity after external load is removed, but after it reaches the plastic phase, deformation is not entirely reversible and with the deformation increasing, the stress of the arch will redistribute. The yield at the vault does not have much effect on the stiffness or bearing capacity of the structure. Plastic hinges formed at 1/4 on both sides of the arch can be used as the sign of instability for elastic-plastic arch.

\subsection{Energy characteristics of arches at dynamic stability critical state}

The instability of elastic-plastic arch can be determined by the forming of plastic hinges at about $1 / 4$ on both sides of the arch, but the stability of an elastic-plastic arch can't still be determined by the movement of the vault shown as Fig. 12. When the arch is impact by a rigid body in impact mass of $1.2 \mathrm{e}^{5} \mathrm{~kg}$, buckling occurs on the arch when the impact velocity increase to $11 \mathrm{~m} / \mathrm{s}$ determined by the forming of plastic hinges at about $1 / 4$ on both sides of the arch. Shown as Fig. 12, when the impact mass is constant, relatively small velocity, such as $10 \mathrm{~m} / \mathrm{s}$, the arch vibrates with a small amplitude at a certain distance from the initial position after impact rather than moves back to its initial position. With the increase of the impact velocity, the maximum displacement of the crown of the arch increases and the vibration amplitude decreases but the arch won't occur snap through buckling like elastic arch shown as Fig. 6. Thus, the critical impact velocity the elastic-plastic arch can bear can't be determined by the movement of the vault.

The mechanical analysis of elastic-plastic arch under impact becomes more complicated. Considering in the static loading process, the elastic strain energy of the arch reaches the maximum when plastic hinges are formed at about 1/4 on both sides of the arch, it is assumed that the elastic strain energy of the arch which can lead to the 
generation of plastic hinges on the arch is certain when the geometry of the arch is constant. The time history curves of elastic strain energy of arches analyzed by FEM are partially given in Fig. 13. The elastic strain energy of the arch under impact applied when the dynamic stability critical state of the arch is reached are indicated by the black solid curves shown in Fig. 13.

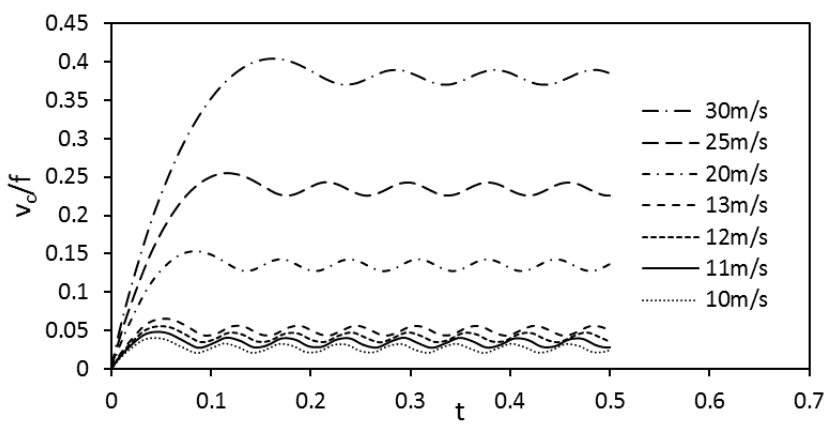

Fig. 12 The curves of crown displacement varying with time under impact when impact mass $=1.2 \mathrm{e}^{5} \mathrm{~kg}$

Taking Fig. 13, c for example, the characteristics of elastic strain energy varying with time of elastic-plastic arch under impact in different initial conditions are analyzed. The time-history curves of elastic strain energy all have obvious indentations at different moments shown as Fig. 13, c, which is because that the impact process goes through two pulses acted on arches shown as Fig. 9 and stress wave transfer causes the indentations appearing at different times. When the impact velocity is relatively large, such as $10 \mathrm{~m} / \mathrm{s}$, the curve goes down to the indentation after a sharp increase which is caused by stress fluctuations when plastic hinges formed, and then the trend of the curve is almost horizontal until the end of the impact process accompanied by the elastic strain energy falls back quickly, which shows that the work done by the second pulse is converted into plastic dissipation and kinetic energy of arch rather than elastic strain energy. The plastic hinges have been formed when the impact velocity is $10 \mathrm{~m} / \mathrm{s}$, thus the dynamic instability of the arch occurred.

Giving the impactor a slightly smaller initial velocity of $8 \mathrm{~m} / \mathrm{s}$, it can be observed that the wave crest before the indentation flattens out which is because the extreme value of the first pulse decreases with the decrease of the impact velocity, but the plastic hinges also formed and the subsequent horizontal duration of the curve is shortened due to the pulse duration of the second pulse is shortened compared with that when impact in initial velocity of $10 \mathrm{~m} / \mathrm{s}$ acting on. A smaller impact velocity than $8 \mathrm{~m} / \mathrm{s}$ would make the wave crest flatter and the subsequent horizontal duration shorter shown as Fig. 13, c until that the impact in critical initial velocity of $6.5 \mathrm{~m} / \mathrm{s}$ act on, the wave crest eventually vanishes and plastic hinges won't form in the whole process of impact. Continuing reducing the impact velocity, instability won't happen on the elastic-plastic arc. Based on the above analysis, it can be considered that the elastic strain energy of the elastic-plastic arch brought about by the first pulse under impact applied with the critical initial impact condition is the critical elastic strain energy for dynamic instability of that elastic-plastic arch. In other words, if the first pulse can make the elastic strain energy of the arch exceed the critical strain energy, plastic hinges will be formed and the arch will buckle.
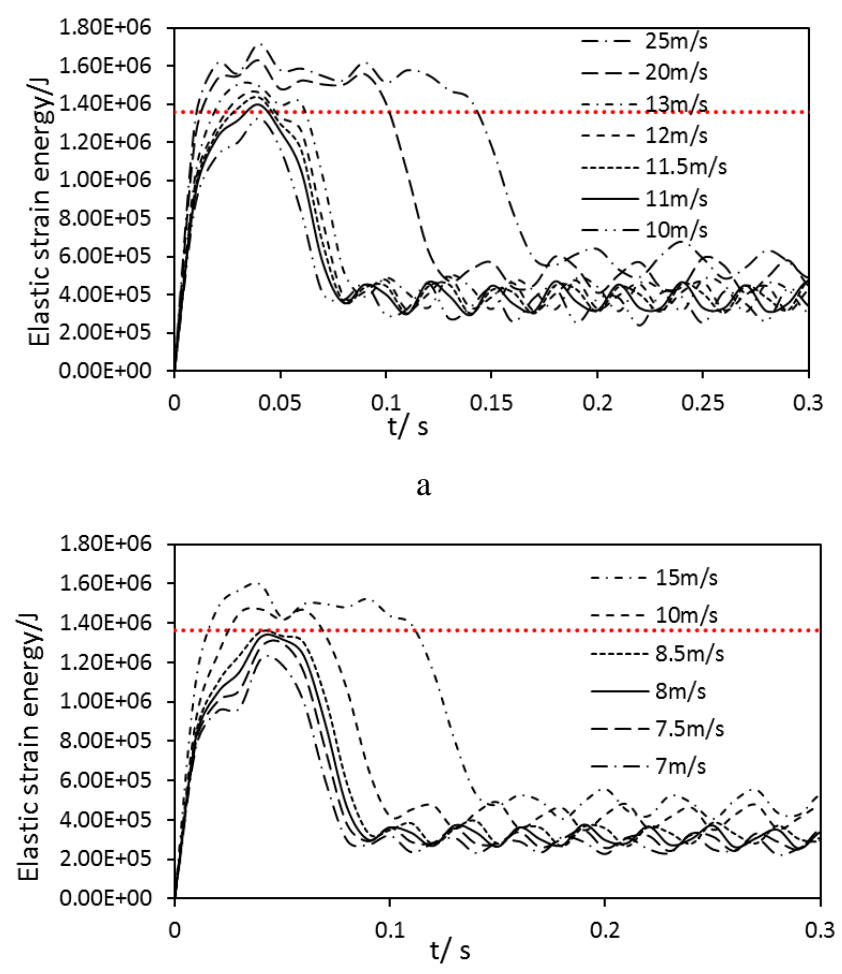

b

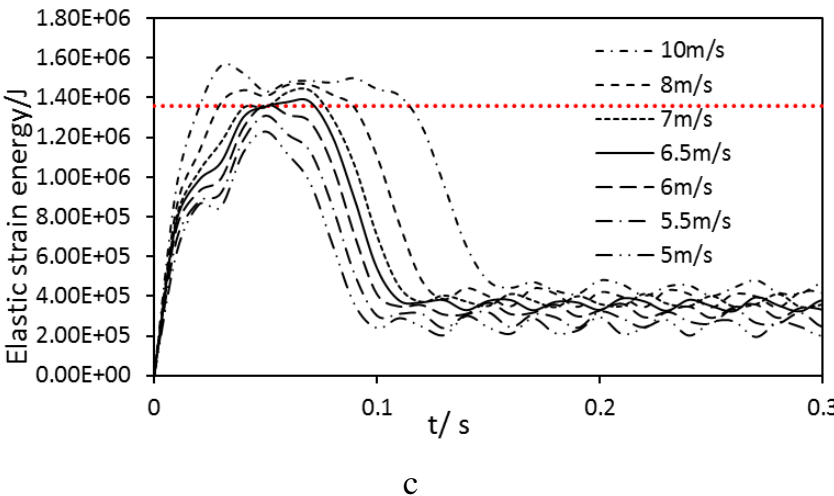

Fig. 13 Elastic strain energy time history curve of elasticplastic arches under impact: a) Impact mass = $=1.2 \mathrm{e}^{5} \mathrm{~kg}$; b) Impact mass $=1.8 \mathrm{e}^{5} \mathrm{~kg}$; c) Impact mass $=2.8 \mathrm{e}^{5} \mathrm{~kg}$

The maximum elastic strain energy value of elastic-plastic arch under static load in the same geometrical dimensions shown as point D in Fig. 10 is marked by horizontal dotted lines shown as Fig. 13 and it could be observed that the maximum elastic strain energy under static load is closed to the critical elastic strain energy for dynamic instability. The elastic strain energy for dynamic and stability critical state analyzed by FEM in this section are listed in Table 5 and difference values between them are very small which are no more than $3 \%$. Thus, it is accurate enough to estimate the critical elastic strain energy of elastic-plastic arch under impact by using the elastic strain energy of the arch when plastic hinges at about $1 / 4$ on both sides of the arch are formed obtained by static loading. 
Table 5

The elastic strain energy of arches

\begin{tabular}{|c|c|c|c|c|}
\hline $\begin{array}{c}\text { Impact } \\
\text { mass, kg }\end{array}$ & $\begin{array}{c}\text { Critical } \\
\text { impact } \\
\text { velocity, } \\
\text { m/s }\end{array}$ & $\begin{array}{c}\text { Strain energy } \\
\text { of arches at } \\
\text { dynamic sta- } \\
\text { ble critical } \\
\text { state, J }\end{array}$ & $\begin{array}{c}\text { Maximum } \\
\text { strain energy } \\
\text { of arches un- } \\
\text { der static load } \\
\text { (point D), J }\end{array}$ & $\begin{array}{c}\text { Percent- } \\
\text { age val- } \\
\text { ues of } \\
\text { the dif- } \\
\text { fer- } \\
\text { ences, } \%\end{array}$ \\
\hline $1.20 \mathrm{E}+05$ & 11.00 & $1.3971 \mathrm{E}+06$ & $1.3603 \mathrm{E}+06$ & 2.699 \\
\hline $1.40 \mathrm{E}+05$ & 9.50 & $1.3523 \mathrm{E}+06$ & $1.3603 \mathrm{E}+06$ & -0.595 \\
\hline $1.60 \mathrm{E}+05$ & 8.50 & $1.3256 \mathrm{E}+06$ & $1.3603 \mathrm{E}+06$ & -2.557 \\
\hline $1.80 \mathrm{E}+05$ & 8.00 & $1.3289 \mathrm{E}+06$ & $1.3603 \mathrm{E}+06$ & -2.314 \\
\hline $2.00 \mathrm{E}+05$ & 7.75 & $1.3407 \mathrm{E}+06$ & $1.3603 \mathrm{E}+06$ & -1.444 \\
\hline $2.20 \mathrm{E}+05$ & 7.50 & $1.3488 \mathrm{E}+06$ & $1.3603 \mathrm{E}+06$ & -0.851 \\
\hline $2.40 \mathrm{E}+05$ & 7.00 & $1.3490 \mathrm{E}+06$ & $1.3603 \mathrm{E}+06$ & -0.835 \\
\hline $2.60 \mathrm{E}+05$ & 6.75 & $1.3665 \mathrm{E}+06$ & $1.3603 \mathrm{E}+06$ & 0.456 \\
\hline $2.80 \mathrm{E}+05$ & 6.50 & $1.3792 \mathrm{E}+06$ & $1.3603 \mathrm{E}+06$ & 1.387 \\
\hline
\end{tabular}

\section{Conclusions}

Based on the energy characteristics of arch under impact, the method for determining the critical state of dynamic stability of both elastic arch and elastic-plastic arch under impact are discussed and conclusions are as follows:

1. By finite element analysis, the stability of the arch can be determined by the movement of the vault both elastic arch under impact. The dynamic instability of the arch can be determined by whether the arch snaps through or not, if the elastic arch does not snap through after impact, it will eventually return to the initial position and vibrate with small amplitude without losing stability. Ideally, when the elastic arch is impacted by the impactor with critical initial conditions of dynamic instability, the motion of the arch almost stopped at its critical stable state and the impactor separated from the arch simultaneously.

2 . It can be concluded from the finite element analyses that when the geometric dimension is determined, the strain energy of the elastic arch at dynamic stable critical state can be accurately estimated by that under static load at the state in which the bearing capacity of the arch drops to zero and the differences between them are very small and no more than $3.6 \%$. Considering the converter efficiencies from initial kinetic energy possessed by the impactor to elastic strain energy of arch approaches $100 \%$ when impact act on the arch with dynamic critical initial conditions that is proved by numerical simulation results, the initial condition of the impact the arch can bear can be determined by static calculation.

3. It has been found from analysis that the instability of elastic-plastic arch can be determined by the forming of plastic hinges at about $1 / 4$ on both sides of the arch. The initial impact conditions which will cause the arch reach the dynamic stable critical state can be obtained through the repeating trial-calculation by FEM.

4. The maximum elastic strain energy of elasticplastic arches under static load is closed to the critical elastic strain energy for dynamic instability and differences values between them are very small which are no more than $3 \%$. It is accurate enough to estimate the critical elastic strain energy of elastic-plastic arch under impact by using the elastic strain energy of the arch when plastic hinges at about $1 / 4$ on both sides of the arch are formed obtained by static loading.

\section{Acknowledgments}

This work was financially supported by National Science Foundation of China (51279206).

\section{References}

1. Pi, Y. L.; Bradford, M. A. 2003. Elasto-plastic buckling and post buckling of arches subjected to a central load, Computers \& Structures 81(18-19): 1811-1825. http://dx.doi.org/10.1016/S0045-7949(03)00204-9.

2. Papangelis, J. P.; Trahair, N. S. 1987. Flexueal-torsional buckling tests on arches, Journal of Structural Engineering 113(7).

http://dx.doi.org/10.1061/(ASCE)07339445(1987)113:7(1433).

3. Dou, C.; Guo, Y. L.; Pi, Y. L.; Zhao, S. Y. 2014. Flexural-torsional buckling and ultimate resistance of parabolic steel arches subjected to uniformly distributed vertical load, Journal of Structural Engineering 140(10: 04014075.

http://dx.doi.org/10.1061/(ASCE)ST.1943541X.0000997.

4. Bruneau, M. 1997. Dynamics of civil engineering structures, Canadian Journal of Civil Engineering 24(5): 847.

http://dx.doi.org/10.1139/197-033

5. Liu, M. S.; Li, J. Y.; Tian, Z. X.; Zhu, C. W.; Ju, J. S. 2017. Effect of impact load on dynamic buckling of steel lattice arch, Strength of Materials 49(1): 45-54. http://dx.doi.org/10.1007/s11223-017-9840-1.

6. Ju, J. S.; Liu, C. Y.; Hou, Z. H.; Zhang, G. K.; Jiang, X. G. 2011. Second-contact analysis of elastic bar impacted by a rigid body, Advanced Science Letters 4(8): 3228-3232. http://dx.doi.org/10.1166/asl.2011.1602.

7. Ju, J. S.; Ding, M.; Shi, X. D.; Cen, S.; Jiang, X. G.; Chen, X. H. 2011. Effect of beam height on elastic impact load subjected to transverse impact of bar, Key Engineering Materials 462-463: 259-264.

http://dx.doi.org/10.4028/www.scientific.net/KEM.462-463.259.

8. Xie, Q.; Jing, L.; Wang, Z. 2013. Deformation and failure of clamped shallow sandwich arches with foam core subjected to projectile impact, Composites Part B: Engineering 44(1): 330-338. http://dx.doi.org/10.1016/j.compositesb.2012.04.070.

9. Koiter, W. T. 2001. Elastic stability and post-buckling behavior, Annual Meeting -1: 257-275.

http://dx.doi.org/10.1007/978-94-009-7538-5_2.

10. Zhu, G.; Huang, Y. G.; Yu, T. X.; Wang, R. 2015. Estimation of the plastic structural response under impact, International Journal of Impact Engineering 4(4): 271282.

http://dx.doi.org/10.1016/0734-743X(86)90018-7.

11. Wang, A.; Tian, W. 2006. Development mechanism of local plastic buckling in bars subjected to axial impact, International Journal of Solids and Structures 43(14-15): 4578-4594. http://dx.doi.org/10.1016/j.ijsolstr.2005.06.091.

12.Sule, S.V.; Sukumar, M.; Weiss, W.F.; Marcelinocruz, A. M.; Sample, T.; Tessier, P. M. 2011. Highthroughput analysis of concentration-dependent antibody self-association, Biophysical Journal 101(7): 
1749-1757.

http://dx.doi.org/10.1016/j.bpj.2011.08.036.

13. Kubiak, T. 2013. Static and Dynamic Buckling of ThinWalled Plate Structures. http://dx.doi.org/10.1007/978-3-319-00654-3.

14. Parkes, E.W. 1955. The permanent deformation of a cantilever struck transversely at its tip, Proceedings of the Royal Society of London, Series A, Mathematical and Physical Sciences 228(1175): 462-476. http://dx.doi.org/10.2307/99638.

15. Hodge, P. G. J. 1959. Plastic Analysis of Structures. McGraw-Hill Book Company, Inc.Jones N. Recent Studies on the Dynamic Plastic Behavior of Structures, J. Applied Mechanics Reviews 1989, 238(42): 95-115. http://dx.doi.org/10.1115/1.3644008.

16. Palomby, C.; Stronge, W. J. 1988. Evolutionary modes for large deflections of dynamically loaded rigid-plastic structures, Mechanics of Structures and Machines 16(1): 53-80.

http://dx.doi.org/10.1080/08905458808960253.

17. Wei, D. 2004. Nonlinear theory of arch and its application M. Beijing: Science Press.

18. Pi, Y. L.; Bradford, M. A. 2008. Dynamic buckling of shallow pin-ended arches under a sudden central concentrated load, Journal of Sound and Vibration 317(35): 898-917. http://dx.doi.org/10.1016/j.jsv.2008.03.037.

19. Pi, Y. L.; Bradford, M. A.; Tin-Loi, F; Gilbert, R. I. 2007. Geometric and material nonlinear analyses of elastically restrained arches, Engineering Structures 29(3): 283-295.

http://dx.doi.org/10.1016/j.engstruct.2006.01.016.
K. Qin, J. Ju, J. Li, M. Liu

\section{DYNAMIC STABILITY OF ARCHES IMPACTED BY RIGID BODY}

S u m m a r y

The dynamic in-plane instability process of pinended arches under a central radial impact applied is analyzed with numerical simulation method. Based on energy characteristics of arch under impact, the method for determining the critical state of dynamic stability of both elastic arch and elastic-plastic arch under impact are discussed in this paper. The calculation results show that the strain energy of the elastic arch at dynamic stable critical state is consistent with that at a state after buckling under static load in which the bearing capacity of the arch drops to zero, and the difference between them are very small and no more than $3.6 \%$. When impact act on the arch with dynamic critical initial conditions, the converter efficiencies from initial kinetic energy possessed by the rigid body to elastic strain energy of arch approaches $100 \%$, therefore a feasible method is provided to determine the dynamic stability of elastic arch under impact on the energy method. Then the impact analysis of arch considering material nonlinearity is carried out, it is proposed that the instability of elastic-plastic arch can be judged by the forming of plastic hinges at about $1 / 4$ on both sides of the arch. It is found that the elastic strain energy of elastic-plastic arch at dynamic stability critical state is very close to maximum elastic strain energy of the arch under static load, and the differences between them are no more than $3 \%$.

Keywords: Rigid body impact; critical stable state; elastic strain energy; material nonlinearity.

Received September 18, 2019 Accepted February 17, 2021

This article is an Open Access article distributed under the terms and conditions of the Creative Commons Attribution 4.0 (CC BY 4.0) License (http://creativecommons.org/licenses/by/4.0/). 